\title{
Study of prevalence and factors associated with Maternal Near Miss (MNM) cases and maternal death at Rajiv Gandhi Government Women and Children Hospital, Pondicherry, India
}

\author{
Rakesh H. J., Valsa Diana*
}

Department of Obstetrics and Gynecology, Rajiv Gandhi Government Women and Child Hospital, Pondicherry, India

Received: 05 January 2018

Accepted: 31 January 2018

\section{*Correspondence:}

Dr. Valsa Diana,

E-mail: valsadiana@gmail.com

Copyright: (C) the author(s), publisher and licensee Medip Academy. This is an open-access article distributed under the terms of the Creative Commons Attribution Non-Commercial License, which permits unrestricted non-commercial use, distribution, and reproduction in any medium, provided the original work is properly cited.

\begin{abstract}
Background: Maternal mortality is a critical event to assess the quality of a health care system. Analysing the maternal near miss provides a good opportunity for assessing the factors responsible for maternal mortality in that area. The objective of this study was to study the clinic-etiological profile of severe maternal morbidity/near miss case in a tertiary public maternity hospital using criteria from maternal near miss review operational guidelines Ministry of Health and Family Welfare, Government of India (2014).

Methods: A prospective observational study included patients admitted to Rajiv Gandhi Government Women and Children Hospital, Pondicherry between August 2016 and July 2017. The patients who met Near Miss Criteria (a set of Clinical, Laboratory and Management based criteria) given by $\mathrm{MoH}$ and FW, Government of India (2014) were enrolled; their clinical and investigation parameters were recorded.

Results: Out of 9583 live births, $27(0.281 \%)$ were near-miss cases. The maternal near miss incidence ratio was low $2.81 / 1000$ live births, because of strict criterion of labelling near-miss cases. Maternal near miss to mortality ratio was $13.5: 1$, and mortality index was $6.89 \%$, lower the index, indicates better quality of care. The mean age of the near-miss patients was 27.75 years. Most of the patients of near-miss were of multipara $\mathrm{n}=17(62.96 \%)$. Majority $\mathrm{n}=$ $16(59.25 \%)$ of patients were at term gestation. The major causes of near miss were severe haemorrhage $\mathrm{n}=11$ (42\%), Hypertension $n=9(35 \%)$ and rupture uterus $n=4(15 \%)$. Major intervention peripartum hysterectomy was needed in $n=7(27 \%)$ and stepwise devascularisation only in another $n=5(19 \%)$ of near miss cases.

Conclusions: Haemorrhage was the leading cause of near miss events. The study of maternal near miss provides an insight into the causes of maternal mortality in this region. The maternal morbidity and mortality can be reduced by providing proper antenatal care at primary and community health centre level and good intensive care and using maternal early warning system (MEWS) at tertiary level. Maternal near miss ratio is worth presenting in national indices.
\end{abstract}

Keywords: Maternal near miss, Peripartum hysterectomy, Postpartum hemorrhage, Rupture uterus

\section{INTRODUCTION}

Maternal mortality is a critical event to assess the quality of a health care system. The standard indicator for measuring this is the Maternal Mortality Ratio (MMR), defined as the ratio of the number of maternal deaths per 100,000 live births. Due to improved health care, there has been decline in MMR globally and in India as well MMR has declined steadily. Maternal mortality (MM) is frequently described as "just the tip of the iceberg", alluding that there is a vast base to the iceberg in the form of maternal near miss (MNM) i.e. maternal morbidity which has remained largely un described. Goal 3 of Sustainable development goal (SDG) aims to reduce the 
global maternal mortality ratio to less than 70 per 100 000 live births By 2030. ${ }^{1}$ In India maternal mortality ratio (MMR) estimates have dropped from 301 maternal deaths per 100,000 live births during 2001-03 to 190 maternal deaths per 100,000 live births during 2011-13. ${ }^{2}$ Due to the success of modern medicine, maternal deaths are fewer in number but there are innumerable "near miss" events which have the potential to teach us lessons. WHO in 2009 defined maternal near miss as "a woman who nearly died but survived a complication during pregnancy, child birth or within 42 days after termination of pregnancy". 3

Women who have survived complications during pregnancy and childbirth have been studied as surrogates of maternal deaths and been termed MNM (maternal near miss). Reviews of such cases are considered a less threatening approach to improve maternal health care by the service providers. As Near Miss occurs much more frequently than maternal deaths, a more reliable quantitative analysis can provide a comprehensive profile of the health system functioning.

There are several advantages of investigating near miss cases e.g. they are more common than maternal deaths, provide useful information on the same pathways that leads to morbidity and death, less threatening for service providers as women has survived, women can be interviewed and as a result more realistic analysis of gaps can be done. Thus, investigating severe maternal morbidity (near-miss) helps to identify women at highest risk of maternal death and helps allocate resources especially in the area where it is needed most.

A woman can only be recognized as a maternal near miss case retrospectively. Per definition, a woman needs to survive the severe complication to become a maternal near miss case.

In order to provide insight into the quality of maternal care in Rajiv Gandhi Government Women and Children Hospital (RGGWCH), Pondicherry. This study was conducted to determine the prevalence and nature of near- miss obstetric cases and maternal deaths.

\section{METHODS}

The study was conducted at Rajiv Gandhi Government Women and Children Hospital, Pondicherry. Ours is a tertiary care institution. It is a referral hospital for both public and private hospitals in Pondicherry and three other surrounding districts in Tamil Nadu, India. In addition to providing twenty-four-hour emergency obstetric services, the hospital also provides antenatal care and delivery services for both low and high risk pregnant. All medical care given to the patient is provided free of cost. This centre provides emergency Obstetric care over $24 \times 7$ days, emergency surgeries, ICU facilities, blood and blood products transfusion, Radiology services (USG, CT), neonatal intensive care unit and other specialist services. Around 750 deliveries are being conducted per month.

It is a prospective observational study in patients who are admitted in our hospital over a period of 12 months from (July 2016 to August 2017) who fulfils the inclusion criteria are included in the study and followed up till discharge. Maternal death during the same period is also analysed and compared with near miss cases. All women who were pregnant, in labour, or who delivered or aborted up to 42 days ago arriving at the facility with potentially life-threatening conditions, and/or received critical interventions, or who came to the facility in lifethreatening condition were included in the study.

Detailed history of patients like name, age of patients, date of admission and presenting complaints were recorded. Obstetrics history including history of previous pregnancy and labour, complication during present pregnancy, past and present medical problems were also recorded. For each case of MNM, the primary obstetric complication leading to severe acute maternal morbidity was evaluated in order to allow comparison with the common causes of maternal mortality.

Institutional Ethics Committee approval was taken before starting the present study. In December 2014 the Ministry of Health and Family Welfare Government of India Maternal Health Division published maternal near miss identifying criteria. ${ }^{4}$ and notification guidelines, so as to accelerate the decline of maternal deaths for achieving our national and international goals. Criteria for identifying and notifying the MNM case have been put under three broad categories:

- Pregnancy specific obstetric and medical disorders,

- Pre-existing disorders aggravated during pregnancy,

- Accidental / Incidental disorders in pregnancy.

Criteria (minimum three from each category) must be met with:

- Clinical findings

- Investigations

- Interventions or any single criteria which signify cardio respiratory collapse.

Pregnancy specific obstetric and medical disorders include severe haemorrhage, sepsis, hypertension, postpartum collapse; pregnancy related liver dysfunction /failure and cardiac dysfunction (e.g. cardiomyopathy). Pre-existing disorders aggravated during pregnancy include anaemia, respiratory dysfunctions, and heart disease, hepatic dysfunction, endocrinal disorders (e.g. diabetic ketoacidosis, thyroid crisis), neurological and renal dysfunction. Accidental/incidental disorders in pregnancy include accidental fall, burns, snake bite, poisoning, drug reactions, transfusion reaction, infection, embolism and infarction. 
Following indices were calculated

- Maternal near miss incidence ration per 1000 live births

- Maternal near miss and mortality ratio

- $\quad$ Mortality index, MD / (MNM + MD) × 100

- Maternal mortality rate.

\section{MNM ratio (MNMR)}

It refers to the number of maternal near-miss cases per 1000 live births $(\mathrm{MNMR}=\mathrm{MNM} / \mathrm{LB})$. This indicator gives an estimation of the amount of care and resources that would be needed in an area or facility.

\section{Maternal near-miss mortality ratio (MNM: $1 \mathrm{MD}$ )}

It refers to the ratio between maternal near miss cases and Maternal Deaths. Higher ratios indicate better care.

\section{Mortality index}

It refers to the number of maternal deaths divided by the number of women with life threatening conditions expressed as a percentage $[\mathrm{MI}=\mathrm{MD} /(\mathrm{MNM}+\mathrm{MD})]$. The higher the index the more women with lifethreatening conditions die (low quality of care), whereas the lower the index the fewer women with lifethreatening conditions die (better quality of care).

Data were entered into a computer database using Microsoft Excel spreadsheet and statistical analysis was performed. Results are presented as frequencies, percentages and descriptive statistics. The prevalence of near-miss cases is defined as the number of near-miss cases divided by the number of deliveries in the hospital.

The frequencies of near-miss events are reported according to the clinical condition responsible. Maternal mortality ratio was calculated as the number of maternal deaths per 100,000 live births.

\section{RESULTS}

During the Twelve months of the study period there were a total of 9632 deliveries and 9583 live births. Total vaginal deliveries were 5872 and 3760 caesarean deliveries. Out of which 27 women were identified as near-miss obstetrical cases using near miss criteria (a set of clinical, laboratory and management-based criteria) given by MoH and FW, Government of India (2014). ${ }^{4}$

Table 1 shows frequency of near miss cases and maternal death. The prevalence of near miss case in this study was $0.281 \%$. Two maternal deaths occurred during study period, resulting in a ratio of maternal death of 20.87 maternal deaths per 100,000 live births.

There were 2 maternal deaths with mean age of 27, with similar demographic profile as near miss cases. Near miss to mortality ratio was $13.5: 1$ which means for every 13 14 life threatening conditions there was one maternal death.

Table 1: Frequency of near-miss cases and maternal death.

\begin{tabular}{|l|l|}
\hline Deliveries & Total \\
\hline Live births & 9632 \\
\hline Near miss cases & 9583 \\
\hline Maternal near miss case per 1000 live birth & 27 \\
\hline Maternal deaths & 2.81 \\
\hline MMR/ 100000 live birth & 2 \\
\hline Maternal death to near miss ratio & 20 \\
\hline Mortality index & $1: 13.2$ \\
\hline
\end{tabular}

Table 2 shows the demographic characteristics of the women classified as near miss cases the median age was 27 ranging from (18-36), 17 (62.9\%) women were multiparous. Prevalence of near miss was more $n=16$ $(59.25 \%)$ in third trimester and was less $n=1(3.73 \%)$ in second trimester.

\section{Table2: Characteristics of near miss cases.}

\begin{tabular}{|l|l|}
\hline Characteristics & Near miss cases n (27) (\%) \\
\hline Age (years) & 27.75 (mean) \\
\hline $18-24$ & 5 \\
\hline $25-30$ & $16(59.25 \%)$ \\
\hline $31-36$ & 6 \\
\hline Parity & 10 \\
\hline Primipara & $17(62.96 \%)$ \\
\hline Multipara & 03 \\
\hline Gestational age in weeks & \\
\hline Upto12 weeks & 01 \\
\hline $12+1$ to 28 weeks & $07(25.9 \%)$ \\
\hline $28+1$ to 37 weeks & $16(59.25 \%)$ \\
\hline $\begin{array}{l}37+1 \text { to } 42 \text { weeks } 8+1 \text { to } \\
37 \text { weeks }\end{array}$ & 27 \\
\hline Total & \\
\hline
\end{tabular}

Table 3 shows mode of delivery of near miss cases, 18 $(66.6 \%)$ patients underwent caesarean delivery of which $15(55.5 \%)$ were emergency caesarean. 2 patients needed suction and evacuation for vesicular mole, out of which 1 patient developed pulmonary embolism immediate post evacuation and other developed post evacuation haemorrhage with suspicion of uterine arteriovenous malformation needing balloon tamponade, uterine artery embolisation and blood transfusion.

Table 4 shows primary obstetric complication leading to near miss cases, Haemorrhage $42 \%(n=11)$ followed by Hypertensive disorders of pregnancy $32 \%(n=9)$ account for majority of cases. We had 4 cases of rupture uterus out of which 2 patients were multipara with previous history of abortions, on low dose oxytocin augmentation 
noted foetal bradycardia taken up for emergency caesarean where rent was noted.

1 patient who was previous one lower segment caesarean at 26 weeks with foetal death was induced with low dose (25mcg) misoprostol developed rupture uterus needing rent repair and blood transfusion. There were 2 cases of anaphylaxis, 1 patient had anaphylaxis to injection Ampicillin and other was a known case of chronic urticaria on irregular treatment developed anaphylaxis.

Table 3: Mode of delivery of near miss cases.

\begin{tabular}{|ll|}
\hline Mode of delivery & $\begin{array}{l}\text { No. Near miss cases } \\
(\%)\end{array}$ \\
\hline Spontaneous vaginal delivery & $3(11.1)$ \\
\hline Caesarean & $18(66.6)$ \\
\hline Emergency & $15(55.5)$ \\
\hline Elective & 03 \\
\hline $\begin{array}{l}\text { Suction and evacuation } \\
\text { (vesicular mole) }\end{array}$ & $02(7.04)$ \\
\hline Laparotomy (rupture uterus) & $04(14.8)$ \\
\hline Total & 27 \\
\hline
\end{tabular}

Table 4: Near miss cases according to primary obstetric complication affecting.

\begin{tabular}{|ll|}
\hline $\begin{array}{l}\text { Primary complication of } \\
\text { pregnancy }\end{array}$ & $\begin{array}{l}\text { No. of maternal near } \\
\text { miss cases }(\mathrm{n}=27) \%\end{array}$ \\
\hline Haemorrhage & $11(42)$ \\
\hline $\begin{array}{l}\text { Hypertensive disorders of } \\
\text { pregnancy }\end{array}$ & $9(32)$ \\
\hline Rupture uterus & $4(15)$ \\
\hline Anaphylaxis & $2(7)$ \\
\hline Respiratory dysfunction & $1(4)$ \\
\hline
\end{tabular}

Table 5 demonstrates the interventions needed in near miss cases, peripartum hysterectomy was needed in $27 \%$ $(n=7), 19 \%(n=5)$ needed only stepwise devascularisation and $15 \% \mathrm{n}=4$ cases needed uterine rent repair only to control postpartum haemorrhage.

Table 5: Mode of Interventions done in near miss cases.

\begin{tabular}{|lll|}
\hline Intervention done & No. of cases & $\%$ \\
\hline Peripartum hysterectomy & 7 & 27 \\
\hline $\begin{array}{l}\text { Stepwise devascularisation } \\
\text { only }\end{array}$ & 5 & 19 \\
\hline $\begin{array}{l}\text { Mechanical ventilation and } \\
\text { cardio tonics }\end{array}$ & 5 & 19 \\
\hline Rent repair & 4 & 15 \\
\hline Blood and blood products & 4 & 15 \\
\hline Dialysis & 2 & 8 \\
\hline Total & 27 & \\
\hline
\end{tabular}

Mechanical ventilation and cardio tonics were needed in $19 \%(n=5)$ cases mainly complicated by hypertensive disorders of pregnancy and anaphylaxis. Dialysis was needed in another 2 patients with acute kidney failure secondary to severe preeclampsia. There were 2 maternal deaths during the study period first was a 29 -year-old primigravida at 38 weeks with latent syphilis delivered vaginally developed Atonic postpartum hemorrhage subsequently needed Peripartum hysterectomy and massive blood transfusion developed Disseminated intravascular coagulopathy. Second case was a 26-yearold at 20 weeks with known case of rheumatic heart disease with severe mitral stenosis subsequently developed pulmonary edema.

\section{DISCUSSION}

The prevalence of near miss case in this study was $0.28 \%$, which was low mainly because of strict criterion of labelling a near-miss case. Range of prevalence of near miss cases varied between $0.4-8 \%$ in a systematic review of maternal morbidity and mortality done by WHO. ${ }^{5}$ This wide variation in range was seen due to the difference in the criteria used for the identification of the near miss cases and the place of study. In another, recent review on articles between January 2004 and December 2010 the prevalence rates of maternal near miss varied between $0.6 \%$ and $14.98 \%$ for disease-specific criteria, between $0.04 \%$ and $4.54 \%$ for management-based criteria and between $0.14 \%$ and $0.92 \%$ for organ-based dysfunction based on Mantel criteria. ${ }^{6}$

The rates are higher in low-income and middle-income countries of Asia and Africa. Based on meta-analysis, the estimate was $0.42 \%$ (95\% confidence intervals CI 0.40$0.44 \%$ ) for the organ dysfunction criteria. ${ }^{6}$

In our institution the most common cause of maternal morbidity is post-partum haemorrhage $(42 \%)$ followed by Hypertensive disorders (35\%) which was similar to most of the previous studies.

The statistics from Kasthuriba hospital, Manipal, India during January 2011-December 2012 (2 years) MNM ratio was 17.8 per 1000 live birth, maternal near miss mortality ratio is 5.6 and mortality index was $14.9 \%$. Haemorrhage was the leading cause of near miss $(44.2 \%)$, followed by hypertensive disorder $(23.6 \%)$ and sepsis $(16.3 \%)^{7}$

Present study mortality index is $6.89 \%$ which is less when compared to studies from tertiary care centres of Bastar 32.7\% and Delhi 22.8\%, In a retrospective study from Damascus maternity university hospital in the year 2006-2007, maternal near miss rate reported was 32.9 per 1000 live birth. ${ }^{8-10}$ Hypertension contributing to $52 \%$ and haemorrhage to $34 \%$. Mortality index being 1.7 which is low when compared with our institution.

In a study reported from medical college of western Rajasthan, using Gellar's scoring system India obstetric near miss rate is 4.18 per 1000 live births. ${ }^{11,12}$ Maternal death to near miss ratio was 1:2.07, major cause for 
maternal near miss is haemorrhage $(58 \%)$ and the second leading cause is hypertension (17.8\%). Incidence of near miss is low, may be because of using Gellar's scoring system. ${ }^{12}$

Our near miss to mortality ratio is 13.5 : 1 which means for every 13 to 14 life threatening conditions there was one maternal death. Syrian study showed a ratio of 60:1 and study done in Nepal showed a ratio of 7.2:1. This ratio is similar to those of African country where the range is 5-12:1.10,13,14 A study from a tertiary hospital Bastar shows 2.05:1 where most of the cases are referred in already moribund state, another study from tertiary care centre Delhi showed 5.4:1.8,9

In present study we found that evaluating disease process at earliest and being alert and ready to manage expected complications is important to save lives of both mother and baby. The higher the mortality index, more the women with the life-threatening conditions dies (low quality of care), while low index suggests better quality of health care.

The low mortality index in our centre is due to better utilization of resources, good antenatal care, good transport facilities and adequate skilled personnel at sub centre, PHC and CHC levels in the states of Pondicherry and Tamil Nadu.

\section{CONCLUSION}

As majority of near miss cases in our study are due to haemorrhage and hypertension it underscores the importance of active management of third stage of labour and need for incorporating Maternal Early Warning System (MEWS) in monitoring third and fourth stages of labour for early detection of deteriorating cases thus reducing delay in action.

The most vital purpose of the near-miss approach is to improve clinical practice and reduce preventable morbidity and mortality through the use of best evidencebased practices Near miss cases are worth presenting as national indices. Auditing of near miss cases helps us in monitoring the quality of hospital-based obstetric care.

\section{ACKNOWLEDGMENTS}

Authors are thankful to their patients without whom this study would not have been possible. Authors are also thankful to Medical Superintendent Dr. Sujatha P. and all the faculty members and staffs of Department of Obstetrics and Gynaecology of the RGGWCH for their Help and support to complete this study.

Funding: No funding sources Conflict of interest: None declared

Ethical approval: The study was approved by the Institutional Ethics Committee

\section{REFERENCES}

1. UNDP. UNDP support to the implementation of the sustainable development goals. Available at http://www.undp.org/content/undp/en/home/libraryp age/sustainable-development-goals/undp-support-tothe-implementation-of-the-2030-agenda/. Accessed $5^{\text {th }}$ January 2018.

2. World Health Organization, UNICEF. Trends in maternal mortality: 1990 to 2013: estimates by WHO, UNICEF, UNFPA, The World Bank and the United Nations Population Division. Available at http://apps.who.int/iris/bitstream/10665/112682/2/97 89241507226_eng.pdf

3. Say L, Souza JP, Pattinson RC. Maternal near miss towards a standard tool for monitoring quality of maternal health care. Best Practice Res Clin Obstet Gynaecol. 2009;23(3):287-96.

4. Maternal near miss review operational guidelines December 2014. Operational Guidelines. Ministry of Health \& Family Welfare. Government of India. Available

at http://www.nrhmorissa.gov.in/writereaddata/Upload/ Documents/Maternal_Near_Miss_Operational_Guid elines.pdf Accessed on January 2018.

5. Say L, Pattinson RC, Gülmezoglu AM. WHO systematic review of maternal morbidity and mortality: the prevalence of severe acute maternal morbidity (near miss). Reproductive Health. 2004;1(1):3.

6. Tunçalp Ö, Hindin MJ, Souza JP, Chou D, Say L. The prevalence of maternal near miss: a systematic review. BJOG. 2012;119(6):653-61.

7. PS R, Verma S, Rai L, Kumar P, Pai MV, Shetty J. Near miss obstetric events and maternal deaths in a tertiary care hospital: an audit. J Pregnancy. 2013;2013.

8. Bansal M, Lagoo J, Pujari K. Study of near miss cases in obstetrics and maternal mortality in Bastar, Chhattisgarh, India. IJRCOG. 2017;5(3):620-3.

9. Sangeeta G, Leena W, Taru G, Sushma K, Nupur G, Amrita P. Evaluation of severe maternal outcomes to assess quality of maternal health care at a tertiary center. J Obstet Gynecol India. 2015;65(1):23-7.

10. Almerie Y, Almerie MQ, Matar HE, Shahrour Y, Al Chamat AA, Abdulsalam A. Obstetric near-miss and maternal mortality in maternity university hospital, Damascus, Syria: a retrospective study. BMC Pregnancy Childbirth. 2010;10(1):65.

11. Kalra P, Kachhwaha CP. Obstetric near miss morbidity and maternal mortality in a tertiary care centre in Western Rajasthan. Indian J PublHealth. 2014;58(3):199.

12. Geller SE, Rosenberg D, Cox S, Brown M, Simonson L, Kilpatrick S. A scoring system identified near-miss maternal morbidity during pregnancy. J Clin Epidemiol. 2004;57(7):716-20.

13. Shrestha NS, Saha R, Karki C. Near miss maternal morbidity and maternal mortality at Kathmandu 
Medical College Teaching Hospital. Kathmandu University Med J. 2010;8(2):222-6.

14. Prual A, Huguet D, Garbin O, Rabe G. Severe obstetric morbidity of the third trimester, delivery and early puerperium in Niamey (Niger). Afr $\mathbf{J}$ Reprod Health. 1998;2(1):10-9.
Cite this article as: Rakesh HJ, Diana V. Study of prevalence and factors associated with Maternal Near Miss (MNM) cases and maternal death at Rajiv

Gandhi Government Women and Children Hospital, Pondicherry, India. Int J Reprod Contracept Obstet Gynecol 2018;7:1048-53. 